Pacific Journal of Mathematic 


\title{
ON THE UNION OF TWO STARSHAPED SETS
}

\author{
D. G. LARMAN
}

Let $S$ be a compact subset of a topological linear space. We shall say that $S$ has the property $\varphi$ if there exists a line segment $R$ such that each triple of points $x, y$ and $z$ in $S$ determines at least one point $p$ of $R$ (depending on $x, y$ and $z$ ) such that at least two of the segments $x p, y p$ and $z p$ are in $S$. It is clear that if $S$ is the union of two starshaped sets then $S$ has the property $\varphi$, and the problem has been raised by $F$. A. Valentine [1] as to whether the property $\varphi$ ensures that $S$ is the union of two starshaped sets. We shall show that this is not so, in general, but we begin by giving a further constraint which ensures the result.

THEOREM. If a compact set $S$, of a topological linear space, has the property $\varphi$, and, for any point $q$ of $S$, the set of points of $R$ which can be seen, via $S$, from $q$ form an interval, then $S$ is the union of two starshaped sets.

Proof. Consider the collection of sets $\left\{T_{q}\right\}, q \in S$, where $T_{q}$ denotes the set of points of $R$ which can be seen, via $S$, from $q$. If every two intervals of this collection have a nonempty intersection, then it follows from Helly's Theorem that $S$ is starshaped from a point of $R$. Suppose, therefore, that there exist points $q_{1}, q_{2}$ of $S$ such that $T_{q_{1}} \cap T_{q_{2}}=\phi$. We partition the collection $\left\{T_{q}\right\}, q \in S$, into three collections $\left\{T_{q}\right\}_{1},\left\{T_{q}\right\}_{2},\left\{T_{q}\right\}_{12}$, so that $T_{q}$ belongs to $\left\{T_{q}\right\}_{1}$ if $T_{q}$ meets $T_{q_{1}}$ but not $T_{q_{2}}, T_{q}$ belongs to $\left\{T_{q}\right\}_{2}$ if $T_{q}$ meets $T_{q_{2}}$ but not $T_{q_{1}}, T_{q}$ belongs to $\left\{T_{q}\right\}_{12}$ if $T_{q}$ meets both $T_{q_{1}}$ and $T_{q_{2}}$. If $T_{q}, T_{r}$ are two sets of $\left\{T_{q}\right\}_{i}(i=1,2)$ then it follows from $\varphi$ applied to the points $q, r$ and $q_{j}(j \neq i)$ that $T_{q}$ meets $T_{r}$. If $T_{q}, T_{r}$ are two sets of $\left\{T_{q}\right\}_{12}$, then, since both $T_{q}$ and $T_{r}$ span the gap between $T_{q_{1}}$ and $T_{q_{2}}$, it follows that $T_{q}$ meets $T_{r}$. Further, if $T_{q}$ belongs to $\left\{T_{q}\right\}_{12}$, then it must meet every set of at least one of the collections $\left\{T_{q}\right\}_{i}(i=1,2)$. For, otherwise, there exists sets $T_{r_{1}}, T_{r_{2}}$, belonging to $\left\{T_{q}\right\}_{1},\left\{T_{q}\right\}_{2}$ respectively, which do not meet $T_{q}$. However, by property $\phi$ applied to $r_{1}, r_{2}$ and $q$, this implies that $T_{r_{1}}$ meets $T_{r_{2}}$ and hence that

$$
T_{r_{1}} \cup T_{r_{2}}
$$

spans the gap between $T_{q_{1}}$ and $T_{q_{2}}$. But this implies that $T_{r_{1}} \cup T_{r_{2}}$ meets $T_{q}$; contradiction. We now form the collections $\left\{T_{q}\right\}_{12 i}(i=1,2)$ so that $T_{q}$ belongs to $\left\{T_{q}\right\}_{12 i}$ if either $T_{q}$ is in the collection $\left\{T_{q}\right\}_{i}$ or $T_{q}$ is in $\left\{T_{q}\right\}_{12}$ and meets every member of $\left\{T_{q}\right\}_{i}$. We note that 


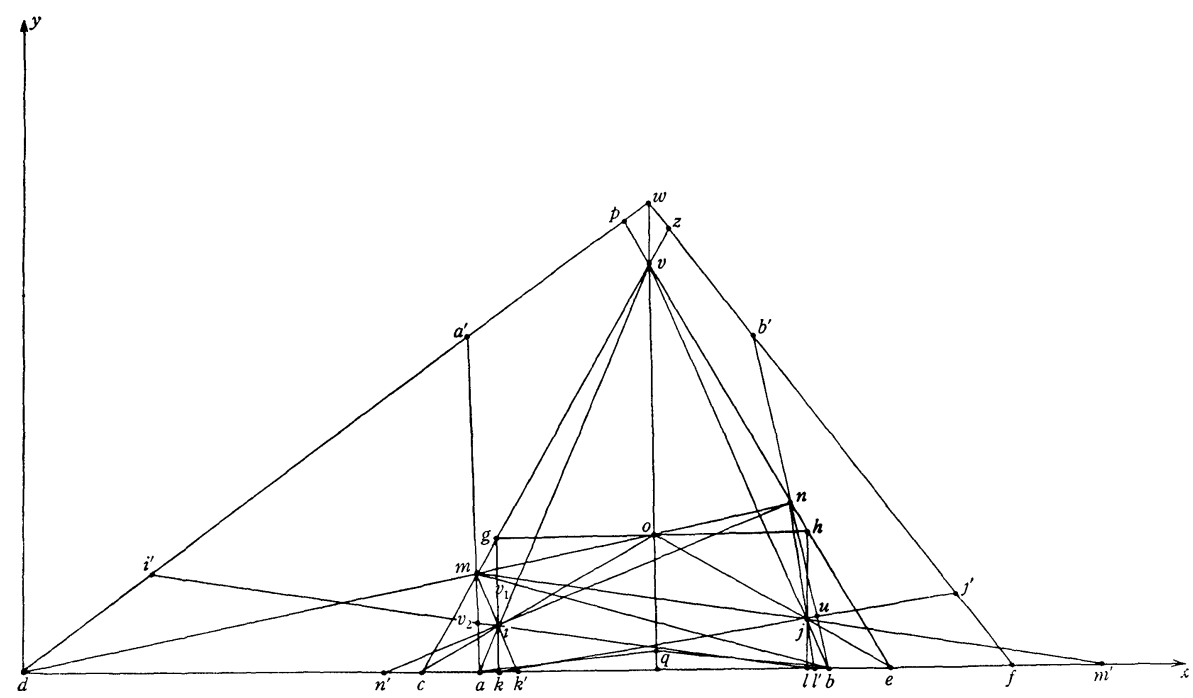

Fig. 1

$$
\left\{T_{q}\right\}_{121} \cup\left\{T_{q}\right\}_{122}=\left\{T_{q}\right\}, q \in S,
$$

and combining the results above with Helly's Theorem, we deduce that the intersection $U_{i}$ of all the members of $\left\{T_{q}\right\}_{12 i}$ is a nonempty closed set. Let $s_{i}$ be a point of $U_{i}$ and let $S_{i}$ be the set of points of $S$ which can be seen, via $S$, from $S_{i}$. Then $S$ is the union of $S_{1}$ and $S_{2}$ which are starshaped from $s_{1}$ and $s_{2}$ respectively.

COUNTER-EXAMPLE. There exists a plane compact set $S$ which has the property $\varphi$ but, nevertheless, cannot be expressed as the union of two starshaped sets.

We assume the existence of a rectangular coordinate system and let $c, e, v$ be the vertices of an equilateral triangle, with $c, e$ on the $x$-axis, $e$ lying to the right of $c$, and $v$ lying above the $x$-axis. Let $o$ be the centroid of the triangle $c e v$ and let the line through $o$, which is parallel to the $x$-axis, meet $c v, e v$ at $g, h$ respectively. Let the vertical line through $g$ meet $c o$ at $i$ and $c e$ at $k$. Let the vertical line through $h$ meet $e o$ at $j$ and $c e$ at $\rho$. Let $v i$ produced meet $c k$ at $a$ and let $v j$ produced meet $\rho e$ at $b$. So far we have defined six distinct points $c, a, k, \rho, b, e$, in that order, on the $x$-axis. Let $d$ be a point on the $x$-axis which lies to the left of $c$ and let the line od produced meet $c g$ at $m$ and $h v$ at $n$. Suppose the lines $m i$ produced, $n j$ produced, meet the $x$-axis at points $k^{\prime}, \rho^{\prime}$, respectively. Let $k g$ meet $m b$ at $v_{1}$ and let $\rho i$ produced meet $a m$ at $v_{2}$. As

$$
d \rightarrow-\infty, \rho^{\prime} \rightarrow \rho, k^{\prime} \rightarrow k, m \rightarrow g, v_{1} \rightarrow g .
$$

Hence we can suppose that $d$ has been chosen as to ensure that (i) 
$k^{\prime}$ and $\rho^{\prime}$ are distinct interior points of $a b$, with $k^{\prime}$ lying to the left of $\rho^{\prime}$, and (ii) the quadrilateral $m v_{1} i v_{2}$ is nondegenerate, and $i$ is closer to the $x$-axis than is $m$. We choose a point $f$ on the $x$-axis and to the right of $e$, and a point $w$ on the line $o v$ produced and strictly above $v$. Let $e v$ produced meet $d w$ at $p$ and let $c v$ produced meet $w f$ at $z$. We also choose a point $q$ on vo produced, which lies strictly above the $x$-axis but which lies below the line segments $a j$ and $b i$. Now, by (ii), the interior $C_{1}$ of the quadrilateral $m v_{1} i v_{2}$ is nonempty, and, if $k j$ produced meets $n b$ at $u$, the interior $C_{2}$ of the triangle jun is nonempty. We define $C_{3}$ to be the interior of the triangle $a q b$ together with the open line segment $a b$. Finally we take $S$ to be $T-C_{1} \cup C_{2} \cup C_{3}$, where $T$ denotes the set within and on $w d f$. Note that by construction every point of $S$, other than those within $v z w p$, can see, via $S$, one of $a$ and $b$, and one of $c, d$ and $e$. We first show that $S$ has the property $\varphi$, with $R \equiv d f$.

Suppose that $p_{1}, p_{2}, p_{3}$ are points of $S$ for which no two can together be seen from any point of $d f$. As any point within $v z w p$ can see each of $c, d$ and $e$, we deduce, from above, that none of $p_{1}, p_{2}, p_{3}$ can lie within $v z w p$. But this implies that each of $p_{1}, p_{2}, p_{3}$ can see one of $a$ and $b$; contradiction. Therefore, we conclude that such a triple of points cannot be chosen in $S$ and hence that $S$ has the property $\varphi$, with $R \equiv d f$.

We now show that $S$ is not the union of two starshaped sets. Suppose, therefore, that $p_{1}, p_{2}$ are points of $S$ and that each point of $S$ can be seen from at least one of $p_{1}, p_{2}$. Let $a m$ produced meet $d w$ at $a^{\prime}$ and let $b n$ produced meet $w f$ at $b^{\prime}$. If neither of $p_{1}, p_{2}$ lie within $a a^{\prime} d$, then neither point can see the interior of the segment $m v_{2}$. Hence $p_{1}$, say, lies within $a a^{\prime} d$ and, similarly, $p_{2}$ lies within $b b^{\prime} f$. Let $i v_{2}$ produced meet $d w$ at $i^{\prime}$ and let $j u$ produced meet $w f$ at $j^{\prime}$. Then $p_{1}$ must lie within $d a v_{2} i^{\prime}$, for, otherwise, the interior of the line segment $v_{2} i$ cannot be seen from $p_{1}$ or $p_{2}$. Similarly $p_{2}$ lies within $f b u j^{\prime}$. Let $n i$ produced meet the $x$-axis at $n^{\prime}$ and let $m j$ produced meet the $x$-axis at $m^{\prime}$. As $p_{2}$ cannot see the interior of the line segment $n j, p_{1}$ must lie within ain'. But then $p_{1}$ cannot see the interior of the line segment $m v_{1}$ and so $p_{2}$ must lie within $j b m^{\prime}$. We note that $p_{1}=a, p_{2}=b$ is impossible and that $i$ and $j$ are the same distance from the $x$-axis. It follows that $p_{1} i$ produced, $p_{2} j$ produced meet at an interior point $g^{\prime}$ of $i j v$. But as $C_{1}$ and $C_{2}$ are nonempty open sets, it follows that there is a nonempty quadrilateral $Q$, which lies within $i j v$ and has $g^{\prime}$ as its lowest vertex, whose interior cannot be seen from either $p_{1}$ or $p_{2}$. As $Q$ lies in $S$, this is a contradiction, and we conclude that $S$ cannot be expressed as the union of two starshaped sets. 


\section{REFERENCE}

1. F. A. Valentine, Convex sets, McGraw-Hill, 1964.

Received December 22, 1965, and in revised form May 2, 1966.

University College, LoNDON, England 


\section{PACIFIC JOURNAL OF MATHEMATICS}

\section{EDITORS}

\section{H. SAMELSON}

Stanford University

Stanford, California

\author{
J. P. JANS \\ University of Washington \\ Seattle, Washington 98105
}

\section{J. DuGUNDJI}

University of Southern California

Los Angeles, California 90007

RichaRd ARENS

University of California

Los Angeles, California 90024

\section{ASSOCIATE EDITORS}

E. F. BECKENBACH
B. H. NeUManN

F. WOLF

K. YOSIDA

\section{SUPPORTING INSTITUTIONS}

UNIVERSITY OF BRITISH COLUMBIA

CALIFORNIA INSTITUTE OF TECHNOLOGY

UNIVERSITY OF CALIFORNIA

MONTANA STATE UNIVERSITY

UNIVERSITY OF NEVADA

NEW MEXICO STATE UNIVERSITY

OREGON STATE UNIVERSITY

UNIVERSITY OF OREGON

OSAKA UNIVERSITY

UNIVERSITY OF SOUTHERN CALIFORNIA
STANFORD UNIVERSITY

UNIVERSITY OF TOKYO

UNIVERSITY OF UTAH

WASHINGTON STATE UNIVERSITY

UNIVERSITY OF WASHINGTON

AMERICAN MATHEMATICAL SOCIETY

CHEVRON RESEARCH CORPORATION

TRW SYSTEMS

NAVAL ORDNANCE TEST STATION

Mathematical papers intended for publication in the Pacific Journal of Mathematics should be typewritten (double spaced). The first paragraph or two must be capable of being used separately as a synopsis of the entire paper. It should not contain references to the bibliography. Manuscripts may be sent to any one of the four editors. All other communications to the editors should be addressed to the managing editor, Richard Arens at the University of California, Los Angeles, California 90024.

50 reprints per author of each article are furnished free of charge; additional copies may be obtained at cost in multiples of 50 .

The Pacific Journal of Mathematics is published monthly. Effective with Volume 16 the price per volume ( 3 numbers) is $\$ 8.00$; single issues, $\$ 3.00$. Special price for current issues to individual faculty members of supporting institutions and to individual members of the American Mathematical Society: $\$ 4.00$ per volume; single issues $\$ 1.50$. Back numbers are available.

Subscriptions, orders for back numbers, and changes of address should be sent to Pacific Journal of Mathematics, 103 Highland Boulevard, Berkeley 8, California.

Printed at Kokusai Bunken Insatsusha (International Academic Printing Co., Ltd.), No. 6, 2-chome, Fujimi-cho, Chiyoda-ku, Tokyo, Japan.

PUBLISHED BY PACIFIC JOURNAL OF MATHEMATICS, A NON-PROFIT CORPORATION

The Supporting Institutions listed above contribute to the cost of publication of this Journal, but they are not owners or publishers and have no responsibility for its content or policies. 


\section{Pacific Journal of Mathematics}

\section{Vol. 21, No. $3 \quad$ BadMonth, 1967}

Richard Allen Askey, A transplantation theorem for Jacobi coefficients . . . 393

Raymond Balbes, Projective and injective distributive lattices .......... 405

Raymond Balbes and Alfred Horn, Order sums of distributive lattices . . . . 421

Donald Charles Benson, Nonconstant locally recurrent functions ........ 437

Allen Richard Bernstein, Invariant subspaces of polynomially compact operators on Banach space ............................... 445

Robert F. Brown, Fixed points and fibre ................... 465

David Geoffrey Cantor, On the Stone-Weierstrass approximation theorem for valued fields ................................ 473

James Walton England, Stability in topological dynamics .............. 479

Alessandro Figà-Talamanca and Daniel Rider, A theorem on random

Fourier series on noncommutative groups.................. 487

Sav Roman Harasymiv, A note of dilations in $L^{p} \ldots \ldots \ldots \ldots \ldots \ldots . \ldots 493$

J. G. Kalbfleisch, A uniqueness theorem for edge-chromatic graphs ....... 503

Richard Paul Kelisky and Theodore Joseph Rivlin, Iterates of Bernstein polynomials .................................... 511

D. G. Larman, On the union of two starshaped sets ............... 521

Henry B. Mann, Josephine Mitchell and Lowell Schoenfeld, Properties of differential forms in $n$ real variables ...................... 525

John W. Moon and Leo Moser, Generating oriented graphs by means of team comparisons .

Veikko Nevanlinna, A refinement of Selberg's asymptotic equation ...

Ulrich Oberst, Relative satellites and derived functors of functors with additive domain ..............................

John Vincent Ryff, On Muirhead's theorem...............

Carroll O. Wilde and Klaus G. Witz, Invariant means and the Stone-Čech compactification 